
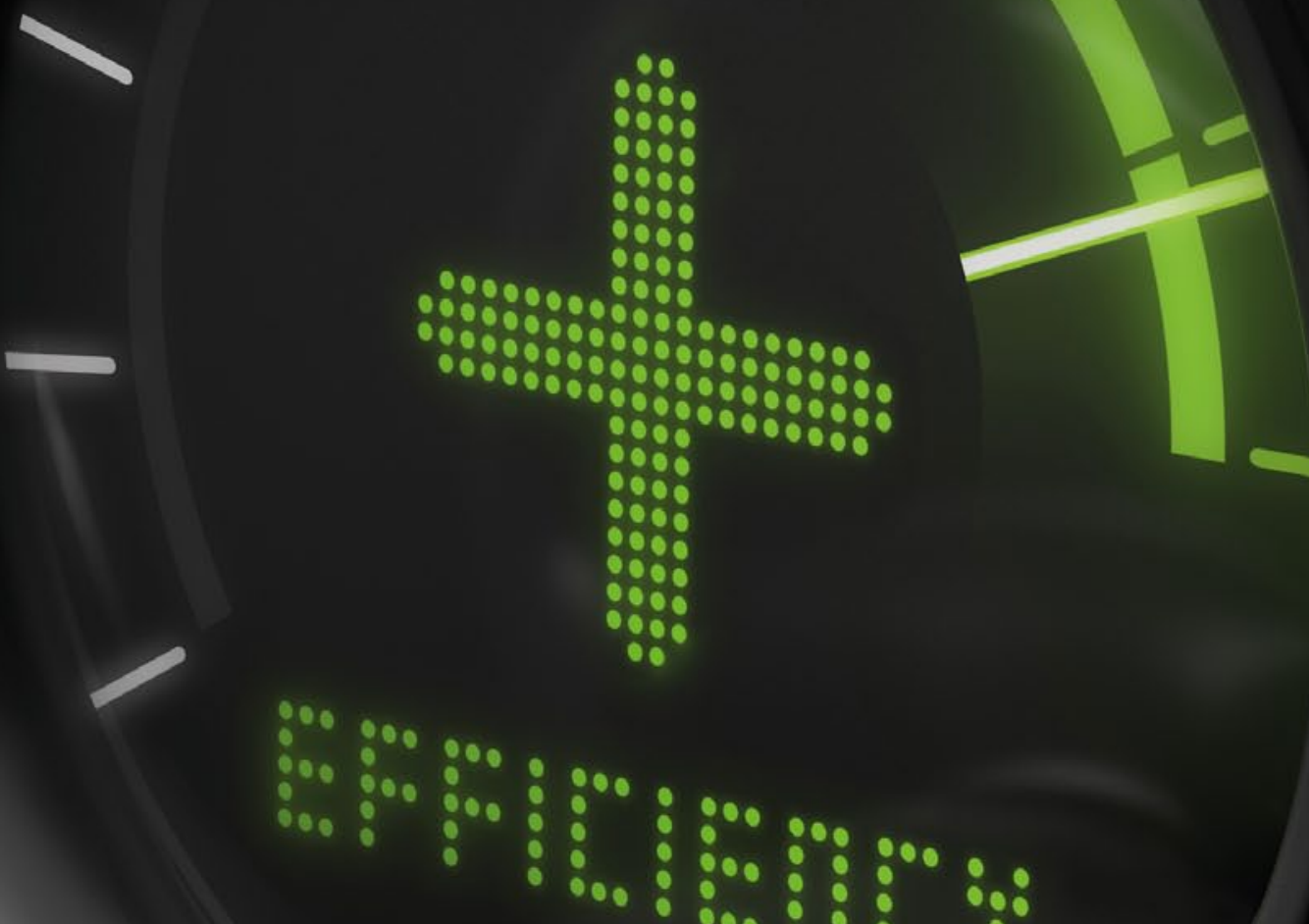

\title{
INTERDISCIPLINARY \\ EXPERTISE IS OPTIMIZING ELECTRIC DRIVES
}

As pure electric traction motors or in hybridized powertrain configurations, electrified drives significantly help to achieve future emissions targets. Electric motors suitable for automotive use must therefore be further optimized in terms of their core efficiency and power-to-weight ratio characteristics in order to increase the drives' ranges. ThyssenKrupp is developing new, innovative solutions through the interdisciplinary cooperation of various product areas combined with extensive materials technology expertise. 